Special Issue of the 6th International Congress \& Exhibition (APMAS2016), Maslak, Istanbul, Turkey, June 1-3, 2016

\title{
Wear Properties of Hybrid Epoxy Composites Reinforced with Carbon/Kevlar/Glass Fabrics
}

\author{
İ. KARTAL* AND H. DEMIRER \\ Marmara University, Faculty of Technology, 34720 Istanbul, Turkey
}

\begin{abstract}
The aim of this study is to investigate the effect of hybridization of fabrics on wear properties of epoxy composites and to relate them to impact properties. With this aim carbon/glass/Kevlar fabrics were hybridized to reinforce epoxy composites. Epoxy composites reinforced with only carbon, glass or Kevlar fabrics were also prepared as reference composites. The wear tests were carried out using a pin-on-disk device. The wear surfaces of composite specimens were examined by scanning electron microscopy to investigate the different behavior of three distinct fabrics in the hybrid composites. The results have shown that carbon fabric reinforced epoxy composite exhibited the highest wear resistance, whereas the wear resistance of Kevlar fabric reinforced epoxy composite was the lowest. As expected, the wear resistance of hybrid composites was lower than that of only carbon fabric reinforced composites.
\end{abstract}

DOI: 10.12693/APhysPolA.131.559

PACS/topics: $81.40 . \mathrm{Pq}$

\section{Introduction}

Nowadays fiber reinforced composite materials are increasingly employed in many areas ranging from simple daily applications to aerospace applications due to their excellent mechanical properties such as high specific strength and increased fatigue life in addition to corrosion resistance. Due to some deficiencies in these materials hybrid reinforced composites have recently been on the agenda of researchers. The term hybrid composite denotes the incorporation of two or more different types of fibers in a common resin matrix. In other words hybrid composites are composed of two or more different types of reinforcements which have different mechanical/physical and/or other properties leading to hybrid effect [1-3]. This type of composite architecture allows researchers to design a composite with tailored properties in demanding applications. In general, the purpose of hybridization is to achieve a composite architecture which synergizes the properties of constituent materials. The resulting structure also gives rise to the cost reductions since one of the fibers could be too expensive [4].

There are several types of structures of hybrid composites such as interply hybrids, intraply hybrids, intimately mixed (intermingled) hybrids, selective placement and super hybrid composites. Aramid/glass, palm/glass, tong glass/mineral fiber etc., are the examples of the hybrid composites having brittle inorganic fibers and ductile organic fibers. Carbon and aramid hybrid is an example of brittle organic and ductile organic hybrids. Although the mechanical properties of conventional composites follow the rule of mixtures, the properties of hybrid composites often positively deviate from the rule of

*corresponding author; e-mail: ilyaskartal@marmara.edu.tr mixtures due to the so-called hybrid effect. The hybrid effect is also important in the wear behavior. Several studies were conducted on wear behavior of composites, including carbon reinforced composites $[2,5,6]$ and Kevlar reinforced composites [7]. However there is no information regarding the wear behavior of hybrid reinforced composites in the public domain. In this study the wear behavior of carbon/glass/Kevlar reinforced hybrid composites will be investigated. The wear properties will then be related to impact performance.

\section{Materials and methods}

Polyacrylonitrile (PAN) based carbon fabrics (UD300 $\mathrm{g} / \mathrm{m}^{2}$ plain), Kevlar fabrics $(400 \mathrm{~g} / \mathrm{m} 2)$, glass fabrics $\left(300 \mathrm{~g} / \mathrm{m}^{2}\right)$ were used in this study. The fabrics were provided by Baykar Makina AŞ. Types of fiber architecture 2D and without surface treatment, were employed. The matrix material used, was a cold curing epoxy resin system Epikote 828 cured by Epicure 205 with an amine accelerator - benzyl dimethylamine, BDMA, (Aldrich) supplied by Hexion in Turkey.

\subsection{Preparation of composite specimens}

Matrix material was prepared out of Epikote 828 epoxy resin and its hardener. The liquid hardener was slowly added to the epoxy resin at room temperature. This mixture was stirred until the two components miscibilised. The efficiency of mixing was judged by the amount of cloudiness visible during the procedure. Well mixed matrix material solutions appear clear, therefore mixing was terminated when this condition was reached. The prepared matrix material was used in the production of seven types of composite specimens. Composite specimens were produced on an aluminum plate through vacuum infusion technique, as shown in Fig. 1. The matrix material content of composites was $30 \%$ by weight. 


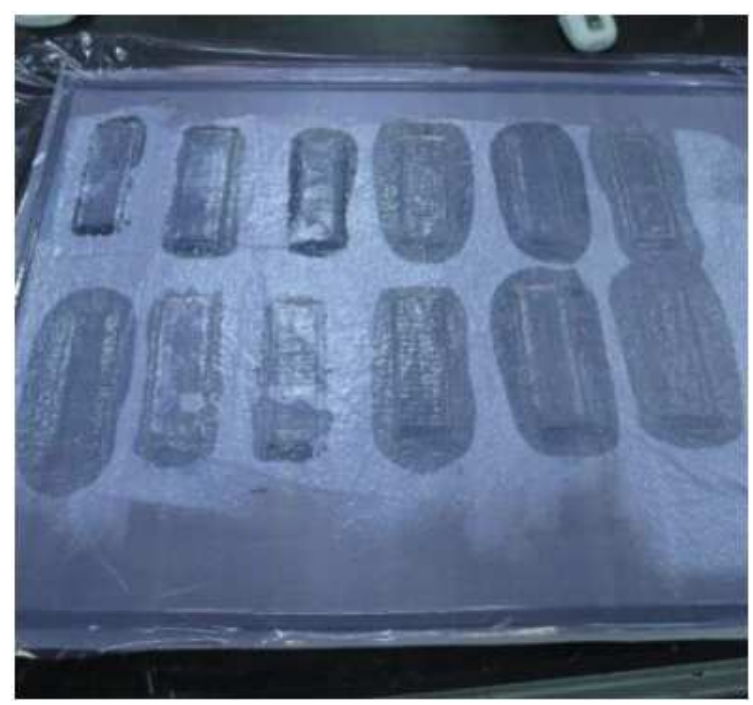

Fig. 1. Vacuum infusion of composite specimens.

\subsection{Characterization}

Izod impact test was conducted with a Zwick B5113.30 tester using $50 \mathrm{~J}$ Izod striker. Abrasive wear studies were carried out on a standard single pin-on-disc machine in dry conditions. The details of the pin-on-disc machine were discussed elsewhere [8]. Prior to the experiment, composites pin with size of $10 \times 10 \times 4 \mathrm{~mm}^{3}$ was abraded. The wear tests were carried out with a continuously rotating D2 tool steel plate of hardness $63 \mathrm{HRC}$ as the counter surface. Disc surface was ground and polished to a roughness of $0.830 \mu \mathrm{m} R a$. All specimens were tested at room temperature, at a constant applied load of $40 \mathrm{~N}$ and a sliding speed of $3 \mathrm{~m} / \mathrm{s}$. Each experiment was repeated for at least three times to ensure the reliability of the test results. The average of the test results was then taken.

Five different sliding distances (1000, 2000, 3000, 4000, $5000 \mathrm{~m}$ ) were employed for the wear tests. After running each sliding distance test, experiment was interrupted and the weight was measured following the careful cleaning of the specimens. The specific wear rate was calculated using the following equation:

$$
W_{\mathrm{s}}=\frac{\Delta m}{\rho L F_{\mathrm{N}}},
$$

where $W \mathrm{~s}$ is the specific wear rate $\left(\mathrm{mm}^{3} / \mathrm{Nmm}\right), \Delta m$ is the mass loss $(\mathrm{g}), \rho$ the density of the materials $\left(\mathrm{g} / \mathrm{cm}^{3}\right)$, $L$ is sliding distance $(\mathrm{mm})$, and $F_{\mathrm{N}}$ is the applied load on the pin $(\mathrm{N})$. The sliding distance was monitored through an auto-recorder. At least three samples were tested under the same conditions to guarantee the reliability of the results.

\section{Results}

The present study deals with the effect of hybridization of fabrics on wear properties of epoxy composites. With this aim seven types of composite were prepared. These are only carbon, glass, Kevlar fabric reinforced composites and carbon/glass, carbon/Kevlar, glass/Kevlar,
carbon/glass/Kevlar hybrid fabric reinforced composites. The effect of fabric content on the density of the composites is given in Fig. 2.

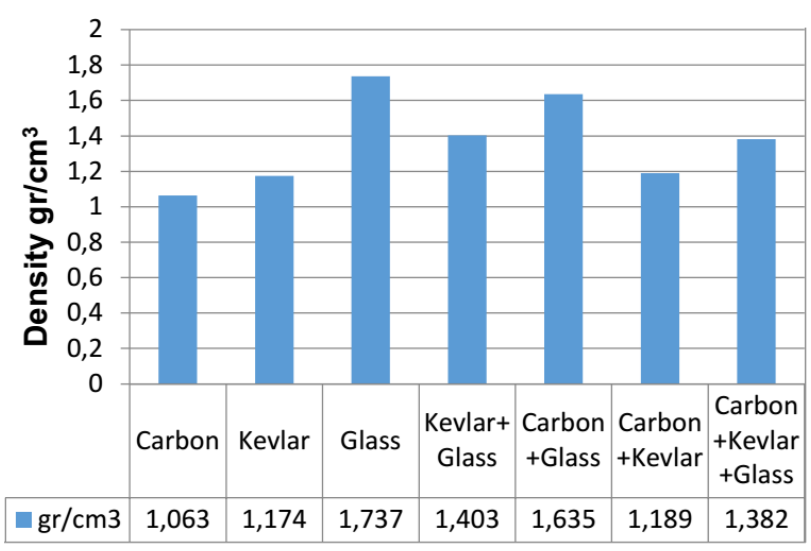

Fig. 2. Density of composite specimens.

As expected, the presence of glass fabric has caused a considerable increase in the density of composites. Glass has the highest density among these three fabrics.

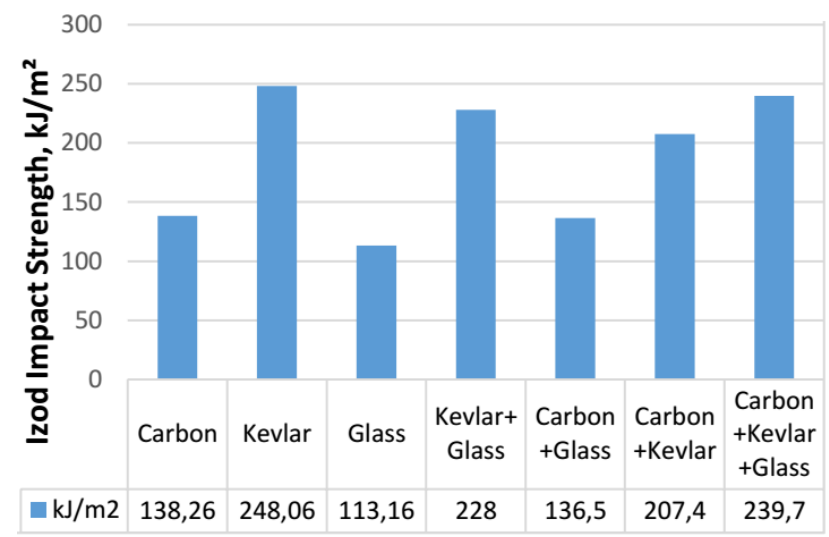

Fig. 3. Izod impact strength properties of composite specimens.

Izod impact strength properties of composite specimens are presented in Fig. 3. The presence of only Kevlar fabric has resulted in the highest impact strength, as expected. For the carbon+Kevlar+glass fabric-reinforced hybrid composites, the presence of Kevlar fabric also had a significant effect on the impact strength. Since the Kevlar is well known for its toughness, improved impact properties were expected in the case of Kevlar fabric utilization in composites.

Variation of mass loss for composites with respect to the wear distance is shown in Fig. 4. As can be seen from Fig. 4, mass loss increases with wear distance for all composite specimens. Only carbon fabric composites have exhibited the lowest mass loss, whereas carbon+Kevlar fabric reinforced composites resulted in the highest mass loss. 


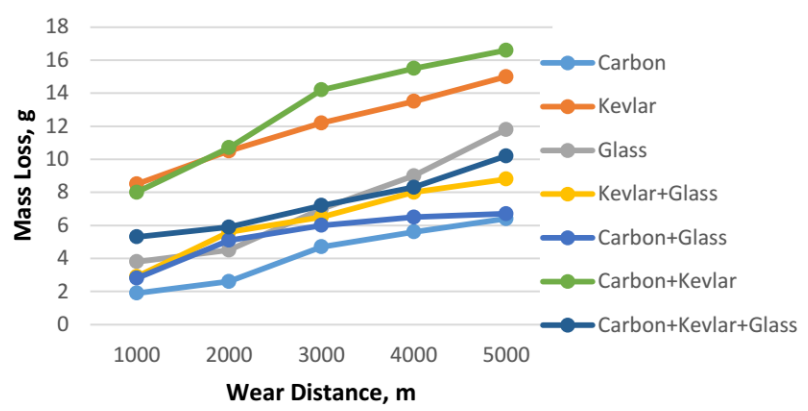

Fig. 4. Variation of mass loss for composites with respect to the wear distance.

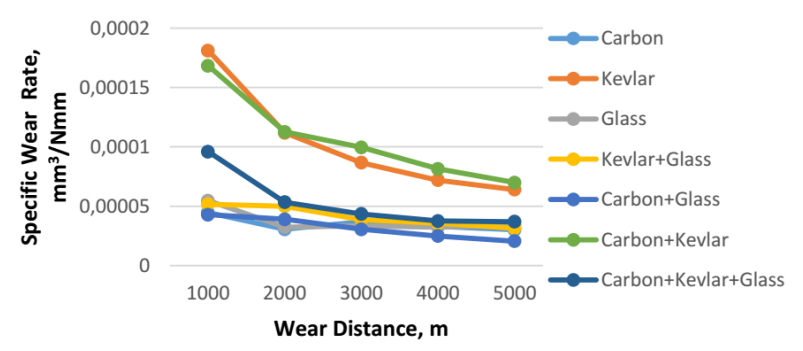

Fig. 5. Variation of specific wear rate for composites with respect to the wear distance.

Variation of specific wear rate for composites with respect to the wear distance is given in Fig. 5. Specific wear rate was the lowest for carbon+glass hybrid composites whereas specific wear rate of carbon+Kevlar hybrid composites was the highest. From the above results it is obvious that the wear resistance of Kevlar was the lowest among the three of the reinforcements. This behavior can be attributed to the orientation of molecules within the structure of the Kevlar fibers. This makes the properties anisotropic. The transverse strength of Kevlar fibers is lower than the longitudinal strength. Therefore, Kevlar fibers have the tendency to form a fibrillary structure when subjected to wear forces [9].

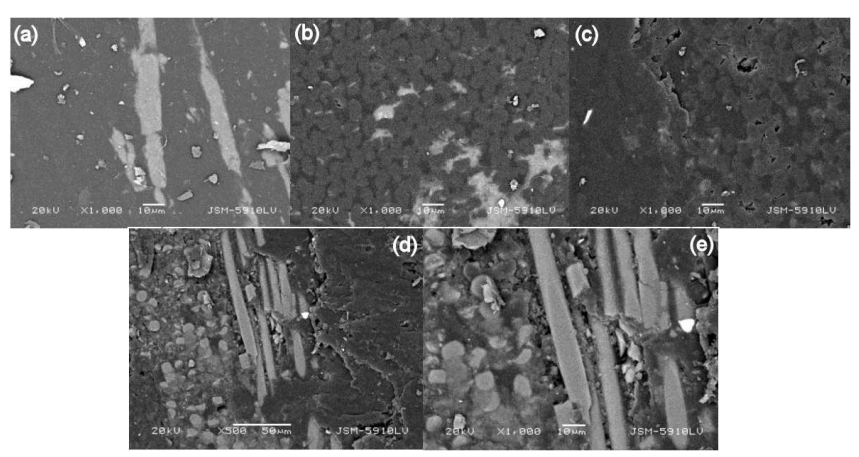

Fig. 6. SEM microphotographs of hybrid composites (a)Kevlar+glass, (b) carbon+glass, (c) carbon+Kevlar, (d)carbon+-Kevlar+glass, (e)carbon+Kevlar+glass.
Scanning electron microscope (SEM) microphotographs of hybrid composites are presented in Fig. 6 as follows, Fig. 6a Kevlar+glass, Fig. 6b carbon+glass, Fig. 6c carbon + Kevlar, Fig. 6d carbon + Kevlar + glass and Fig. 6e carbon+Kevlar+glass.

SEM microphotographs of hybrid composites reveal different wear behavior of the three different fabrics used in the hybrid composites. As can be seen from the SEM microphotographs in Fig. 6a, c and d, the worn Kevlar had adhered to the surfaces.

\section{Conclusions}

In this study the wear behavior of various hybrid composites was investigated. The presence of only Kevlar fabric resulted in the highest impact strength as expected. Kevlar fabric also had a significant effect on the impact strength of carbon+Kevlar+glass fabric reinforced hybrid composites. Only carbon fabric composites exhibited the lowest mass loss. The presence of Kevlar fabric in hybrid composites caused a considerable increase in mass loss. Specific wear rate was the lowest for carbon+glass hybrid composites. Wear resistance of Kevlar reinforced composites was lower than in both glass and carbon reinforced composites. In these sets of hybrid composites, there was an inverse relation between impact strength and wear properties.

\section{References}

[1] L.Y. Lin, J.H. Lee, C.E. Hong, G.H. Yoo, S.G. Advani, Compos. Sci. Tech. 66, 2116 (2006).

[2] V.K. Polineni, A. Wang, A. Essner, R. Lin, A. Chopra, C. Stark, J.H. Dumbleton, ASTM Spec. Tech. Pub. 1346, 266 (1998).

[3] K. Dong, J. Zhang, M. Cao, M. Wang, B. Gu, B. Sun, Polym. Test. 55, 44 (2016).

[4] Y.Z. Wan, J.J. Lian, Y. Huang, F. He, Y.L. Wang, H.J. Jiang, H.Y. Xin, J. Mater. Sci. 42, 1343 (2007).

[5] C.K. Schreiber, Br. Dent. J. 13721 (1974).

[6] S.W. Ha, A. Gisep, J. Mayer, E. Wintermantel, H. Gruner, M. Wieland, J. Mater. Sci. Mater. Med. 8, 891 (1997).

[7] G.V.B. Cochran, V.R. Palmieri, R.E. Zickel, Clin. Biomech. 9, 315 (1994).

[8] J.J. Rajesh, J.T. Bijwe, U.S. Tewari Wear 252, 769 (2002).

[9] S. Fakirov, D. Bhattacharya, Synthetic PolymerPolymer Composites, Hanser Publishers, 2012, p. 465. 